\title{
Managing Natural Products
}

Over the past ten years, natural products have become quite popular in the United States; about $60 \%$ of

Americans use natural products daily.

Herbs and other botanicals, vitamins, minerals, amino acids, and other natural products are sold as dietary supplements in the United States rather than as over-the-counter (OTC) or prescription products. Because they are sold and marketed as dietary supplements, they are not held to the same level of rigorous preapproval testing for safety and efficacy as pharmaceutical products. Although many of these products can be beneficial and there are few reported problems, the potential for serious health problems does exist. These potential problems can be due to allergic reactions, interactions between natural products, interactions between natural products and OTC or prescription medications, interactions between natural products and disease states, or even poor quality or contamination of the product. Because the potential for serious problems is real, as recently addressed by the Department of Health and Human Services, Office of the Inspector General, issues and information on managing natural products in a managed care environment are presented here.

The goal of this continuing education program is to present information, options, and resources to help pharmacists in managed care settings manage the use of natural products in their patient populations.

KEYWORDS: Natural products, alternative medicines, herbals, botanicals

J Managed Care Pharm 2001: 414-19

\section{by Mary J. Ferrill and Linda L. Norton}

0 ince 1962 when the U.S. Food, Drug, and Cosmetic Act was amended, Americans have known that medications in the United States have been subjected to a tremendous amount of research and scrutiny. These efforts have been intended to ensure that both over-the-counter (OTC) and prescription medications were proven safe and effective prior to reaching the U.S. market. With few exceptions, the research and scrutiny has paid off, and serious problems associated with medications have been identified prior to Food and Drug Administration (FDA) approval. The research and analysis that occurs prior to final approval requires enormous amounts of documentation and huge amounts of money even if the medication does not receive FDA approval. Recent estimates for the costs and time associated with the drug-approval process exceed $\$ 230$ million and more than 12 years to completion. ${ }^{1}$

Interestingly, even after the 1962 amendment, natural products (e.g., herbs and other botanicals, vitamins, minerals, amino acids) continued to be sold. Although they were often promoted based on their potential to improve health and increase wellness, they were marketed as foods or food supplements rather than as medicinals, and were often sold in health food stores or in exercise or nutrition centers, and therefore were not subject to the FDA process. In 1993 the FDA reviewed the marketing and sales of these food and food-supplement products and determined that something needed to be done to provide controls. After much research, debate, and even a massive letter-writing campaign by the general public, Congress, rather than the FDA, passed the Dietary Supplement Health and Education Act (DSHEA) of 1994.

In contrast to the process mandated by the 1962 amendment for approval and marketing of medicinal products, the process for marketing a dietary supplement in the United States is streamlined. DSHEA is different from much of the previous legislation and regulations that applies to the FDA. Prior legisIation was often intended to protect the consumer from unsafe products or exposure to products with little or no efficacy. DSHEA is based on the concept that "legislative action that protects the right of access of consumers to safe dietary supplements is necessary to promote wellness." ${ }^{2}$ It allows natural products such as those derived from plants and animals, vitamins, minerals, and amino acids to be sold as dietary supplements. Under some limited circumstances manufacturers of new dietary supplement ingredients (i.e., never before marketed as a food or food substance) must notify the FDA 75 days before marketing the product and must include safety information for the new ingredient. However, it is generally accepted that dietary supplements can be marketed as long as good man- 


\section{TA B LE 1 Limitations of Current Natural Products}

- The active ingredient(s) may not be known.

- The exact mechanism of action of many natural products is unknown or is in question.

- Studies on biopharmaceutics, pharmacokinetics, and pharmacodynamics are often lacking.

- Data on use in pregnancy and lactation are limited.

- Products may not be standardized for purity or potency.

- Products may contain multiple ingredients.

- Products may be adulterated.

- Product dosages may not be standardized (for many products, no dose-ranging studies have been conducted).

- Products may be misidentified (or there may be variations between the label and the package contents).

- Crop conditions may cause batch-to-batch and year-to-year variability in the concentration and milligram weight of the active ingredients in these products.

- Studies and information on children, the elderly, those with renal impairment, etc., are lacking.

ufacturing practices are followed and therapeutic claims are not printed on the product label. Under DSHEA, the labeling on dietary supplements must state that the product has not been evaluated by the FDA. Manufacturers are allowed to describe the dietary supplement's ability to affect "structure or function in humans," and brochures or supplementary documentation may present "a balanced view of the available scientific information." DSHEA does not require that the manufacturer prove the safety or efficacy of their products. Instead, the burden of proof is on the FDA. Under DSHEA, the FDA must prove that a natural product is not safe for human use before it can remove the product from the market.

This streamlined process has made it much less expensive and much easier to market dietary supplements than medications. Therefore, few companies that market these products apply for FDA approval. In some cases, the natural product has been used in folklore or in home or traditional remedies for hundreds or even thousands of years. In many cases the requirements for acquiring a patent to protect the product from competition cannot be met. This lack of protection prevents some companies from investing in the level of product research that would be necessary to meet the FDA requirements for approval of the product through the new-drug approval process. Therefore, only a small number of natural products have ever gone through the FDA new-drug approval process. Two examples of products that are currently marketed as medications are the laxative products senna and cascara.

\section{Quality Issues}

The effect of DSHEA is that health care organizations and professionals, including managed care organizations (MCOs) and pharmacists, have little assurance that natural products are safe or effective for their patients to use. Therefore, a critical analysis of the available medical literature and product information must be conducted to determine the potential problems and quality issues associated with each natural product. Even the process of using available literature to determine whether each natural product reviewed can be considered reasonably safe and possibly effective to prevent and/or treat disease in humans is difficult. Some of the reasons behind this difficulty are listed in Table 1, this page.

A major concern related to the lack of rigorous qualitycontrol procedures and standardization is that product content may vary from one batch to another and from one manufacturer to another. Even if manufacturers fully utilize quality-control measures and standardize the major ingredients in their products, some natural products manufacturers cannot be certain that they are controlling just for the actual active ingredient, or that all the potentially active ingredients are contained within their products. For example, there has been debate as to the true active ingredient in St. John's wort. A group of investigators has recently shown that hyperforin may be the ingredient that gives St. John's wort its antidepressant activity, but most products available in the United States do not contain enough hyperforin. ${ }^{3}$ Unfortunately, all of the studies to date that have attempted to use a standard amount of what was believed to be the active ingredient in St. John's wort have used products standardized to hypericin. As demonstrated by this example, many of the studies upon which practitioners must depend for current safety and efficacy recommendations may not reflect the true active ingredient(s) of products.

To make matters even more complex, many studies of natural products failed to analyze the ingredients in the products that they were using, and were not able to ensure that the natural product used in the study truly contained the ingredient believed to be under consideration (i.e., the "ginseng" product truly contained ginseng). Studies that have looked at the ingredients of natural products have shown a wide variation in the amount of the active ingredient in products. Results of these studies have ranged from none or subclinical amounts of the product located to several times that suggested as "standard. ""-14 O ne last complication is specific to plant-based products. For many botanical products the portion of the plant that confers activity is in question. Some companies may use the entire plant, or just the leaves, sap, roots, stems, fruit or berries, or any combination of plant sections. Herbal experts have even speculated that components of the entire plant act in a synergistic fashion to cause the desired effect, and some products even combine different herbs together (see Table 2, page 416).

\section{Options for Managed Care Organizations and Pharmacists}

In light of these issues, MCOs and pharmacists have several options. At one extreme, they may choose to avoid the naturalproduct issue entirely and deal only with adverse reactions that 
TA B LE 2 Examples of Quality Problems with Natural Products

\begin{tabular}{l|l}
\hline Product & Documented Quality Problem \\
\hline Echinacea & A study examined 25 products and found that only 14 (56\%) passed quality testing. \\
\hline Ginkgo & A study examined 32 ginkgo products and only 25 passed the basic criteria for content. \\
\hline Ginseng & $\begin{array}{l}\text { A study examined } 22 \text { products and found that only } 9 \text { met quality and purity standards. A recent } \\
\text { study looked at } 25 \text { products in the United States and found that only } 11 \text { products had specific label- } \\
\text { ing as to the concentration; six contained low concentrations, five contained high concentrations. }\end{array}$ \\
\hline Glucosamine and chondroitin & $\begin{array}{l}\text { Fourteen products containing glucosamine hydrochloride or glucosamine sulfate, and } 11 \text { products } \\
\text { containing chondroitin were studied. The contents varied from } 0 \%-115 \% . \text { In another study of } 25 \\
\text { products tested, nearly one-third did not pass testing standards. }\end{array}$ \\
\hline Melatonin & $\begin{array}{l}\text { One study examined the quality of } 11 \text { melatonin products and found a wide variation in the quality } \\
\text { of the products. Another examined } 19 \text { products and found that only } 9 \text { passed the quality criteria. }\end{array}$ \\
\hline St. John's wort & $\begin{array}{l}\text { A study showed that } 7 \text { of the } 21 \text { products, one-third, did not pass testing for quality. Five of the } \\
\text { products contained unacceptably high levels of cadmium. (Cadmium naturally accumulates as the } \\
\text { St. John's wort plant grows.) Only } 2 \text { of the } 21 \text { products mentioned hyperforin content, and one had } \\
\text { suboptimal amounts. }\end{array}$ \\
\hline Saw palmetto & $\begin{array}{l}\text { Only } 17 \text { of } 21 \text { products tested were of adequate quality. } \\
\text { Valerian }\end{array}$ \\
\hline Source: See references 4-14 & In a study that examined 17 products, only 9 passed the quality test. \\
\hline
\end{tabular}

(TA B LE 3 Selected Options for Managing Natural Products

\begin{tabular}{|c|c|c|c|c|c|c|c|}
\hline & \multicolumn{7}{|c|}{ Level of Commitment to Managing Natural Products } \\
\hline & \multicolumn{7}{|c|}{ 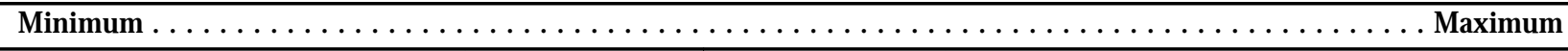 } \\
\hline \multicolumn{8}{|l|}{ Option \# } \\
\hline$\overline{1}$ & $\mathrm{x}$ & & & & & & \\
\hline 2 & $\mathrm{x}$ & $\mathrm{x}$ & & & & & \\
\hline 3 & $x$ & $\mathrm{x}$ & $\mathrm{x}$ & & & & \\
\hline 4 & $\mathrm{x}$ & $\mathrm{x}$ & $\mathrm{x}$ & $\mathrm{x}$ & & & \\
\hline 5 & $\mathrm{x}$ & $\mathrm{x}$ & $x$ & $\mathrm{x}$ & $\mathrm{x}$ & & \\
\hline 6 & $\mathrm{x}$ & $\mathrm{x}$ & $\mathrm{x}$ & $\mathrm{x}$ & $\mathrm{x}$ & $\mathrm{x}$ & \\
\hline \multirow[t]{4}{*}{7} & $\mathrm{x}$ & $\mathrm{x}$ & $\mathrm{x}$ & $\mathrm{x}$ & $\mathrm{x}$ & $\mathrm{x}$ & $\mathrm{x}$ \\
\hline & $\begin{array}{l}\text { Response to } \\
\text { adverse effects } \\
\text { only }\end{array}$ & $\begin{array}{l}\text { If practitioner is } \\
\text { knowledgeable, } \\
\text { natural-products } \\
\text { information on } \\
\text { request }\end{array}$ & $\begin{array}{l}\text { Practitioners } \\
\text { competency in } \\
\text { natural products } \\
\text { required by } \\
\text { contract, } \\
\text { information on } \\
\text { request }\end{array}$ & $\begin{array}{c}\text { Active } \\
\text { dissemination of } \\
\text { natural-products } \\
\text { information to } \\
\text { all patients }\end{array}$ & $\begin{array}{c}\text { Specific } \\
\text { recommendations } \\
\text { for or against } \\
\text { natural products }\end{array}$ & $\begin{array}{l}\text { Natural } \\
\text { products as } \\
\text { a covered } \\
\text { benefit }\end{array}$ & $\begin{array}{c}\text { Visits to } \\
\text { natural- } \\
\text { products } \\
\text { practitioners } \\
\text { as a covered } \\
\text { benefit }\end{array}$ \\
\hline & \multicolumn{7}{|c|}{ Possible Level of Risk (Liability) and Benefit Related to Managing Natural Products } \\
\hline & Minimum Lel & 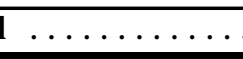 & מ & $\cdots$ & $\ldots \ldots \ldots$ & $\ldots \ldots M$ & kimum Level \\
\hline
\end{tabular}

cause members or patients to use resources or ask questions. However, without information and guidance, patients may not consider these products to be "medications" and may not report product use and associated problems to pharmacists and physicians. Or, at the other extreme, MCOs and pharmacists may embrace natural products, recommending their use when reasonable or even providing a coverage benefit for natural products and natural-product practitioners. Of course, there are many options between the extremes. Once an option is selected, that option may be steadfastly maintained, or practitioners and organizations may chose to allow the patient and the circumstance to dictate additional choices. Each choice is associated with potential risks and benefits for both patients and the MCO or pharmacist (See Table 3, above).

When natural products are recommended or provided as a covered option in health care, patients may have increased satisfaction with their health, their health care coverage, and their health care providers, and they may experience improved health outcomes. Additionally, the use of the prescription-medication benefit may decrease, and in many cases, the decrease may be appropriate. 
Managing Natural Products

\section{TA B LE 4 Ten References for Information on Natural Medicines}

\begin{tabular}{|c|c|c|c|c|c|}
\hline Reference & $\begin{array}{c}\text { Year \& } \\
\text { Edition Updates }\end{array}$ & $\begin{array}{c}\text { ISBN/ISSN/ } \\
\text { Contact Information }\end{array}$ & Availability & Referenced & Contents \\
\hline $\begin{array}{l}\text { Alternative M edicine } \\
\text { Alert: A Clinician's } \\
\text { Guide to Alternative } \\
\text { Therapies }\end{array}$ & $\begin{array}{c}\text { Updated } \\
\text { monthly, indexed } \\
\text { yearly }\end{array}$ & $1096-942 X$ & $\begin{array}{l}\text { Newsletter } \\
\text { and online }\end{array}$ & Yes & $\begin{array}{l}\text { Monthly newsletter on alternative topics directed } \\
\text { toward physicians. Provides information on } \\
\text { common and timely alternative-medicine topics. } \\
\text { Information is analyzed and highly referenced. } \\
\text { Not as useful as a standard alternative-medicine } \\
\text { monograph "drug-type" reference. }\end{array}$ \\
\hline $\begin{array}{l}\text { Guide to Popular } \\
\text { Natural Products }\end{array}$ & $\begin{array}{c}2001 \\
\text { updated yearly }\end{array}$ & $1-57439-063-5$ & Handbook & Yes & $\begin{array}{l}125 \text { products, abridged from Review of } \\
\text { Natural Products. Introductory legal section. } \\
\text { Helpful appendices such as therapeutic } \\
\text { use index. Some photographs. }\end{array}$ \\
\hline $\begin{array}{l}\text { IBIS Integrative } \\
\text { BodyM ind } \\
\text { Information System }\end{array}$ & Updated & $\begin{array}{l}\text { www.teleport.com ibis } \\
\text { 877-526-IBIS }\end{array}$ & $\begin{array}{l}\text { CD-ROM } \\
\text { and online }\end{array}$ & Yes & $\begin{array}{l}\text { Has information on more than } 2,400 \text { alternative } \\
\text { medicines and } 282 \text { common medical conditions; } \\
\text { offers treatments for more than } 12 \text { systems (e. g., } \\
\text { cardiovascular, nervous) of integrative medicine } \\
\text { and alternative therapies. Has note-taking and } \\
\text { report-generating features. Can make personalized } \\
\text { patient-education materials. Directed toward } \\
\text { physicians. }\end{array}$ \\
\hline IBIS Interactions & Updated & $\begin{array}{l}\text { www.teleport.com ibis } \\
\text { 877-526-IBIS }\end{array}$ & $\begin{array}{l}\text { CD-ROM } \\
\text { and online }\end{array}$ & Yes & $\begin{array}{l}\text { Database that contains information } \\
\text { on drug-herb and drug-nutrient interactions. }\end{array}$ \\
\hline $\begin{array}{l}\text { Natural M edicines } \\
\text { Comprehensive } \\
\text { Database }\end{array}$ & $\begin{array}{l}\text { Text updated } \\
\text { yearly, online } \\
\text { continually }\end{array}$ & $\begin{array}{l}\text { www.naturaldatabase.com } \\
\text { or 209-472-2244 }\end{array}$ & $\begin{array}{l}\text { Paperback } \\
\text { and online }\end{array}$ & Yes & $\begin{array}{l}\text { Contains information on alternative "drugs." } \\
\text { Monograph-type information that contains } \\
\text { such topics as "people use this for," effectiveness; } \\
\text { comment; interactions with herbs and other } \\
\text { dietary supplements drugs, foods, labs, diseases, } \\
\text { or conditions. Notes if there are no interactions } \\
\text { known or predicted to occur, insufficient reliable } \\
\text { information, or interactions with some expected } \\
\text { outcomes or potential problems. }\end{array}$ \\
\hline $\begin{array}{l}\text { Natural Products } \\
\text { Explorer }\end{array}$ & $\begin{array}{l}\text { Updated } \\
\text { annually }\end{array}$ & $1-57439-069-4$ & CD-ROM & Yes & $\begin{array}{l}\text { Combination product that contains both The } \\
\text { Review of Natural Products and The } \\
\text { German Commission E M onographs. }\end{array}$ \\
\hline $\begin{array}{l}\text { Natural Therapeutics } \\
\text { Pocket Guide }\end{array}$ & $2000-2001$ & $0-916589-80-3$ & Handbook & Yes & $\begin{array}{l}\text { Topics listed by conditions. Includes herbs, } \\
\text { nutritional supplements, homeopathic } \\
\text { remedies, and lifestyle modifications. }\end{array}$ \\
\hline $\begin{array}{l}\text { PDR for Herbal } \\
\text { Medicines }\end{array}$ & $\begin{array}{c}2000 \\
\text { updated annually }\end{array}$ & $1-5636-3361-2$ & Hardbound & Yes & $\begin{array}{l}\text { Over } 700 \text { monographs. Contains several } \\
\text { indexes: Common name, therapeutic use, side } \\
\text { effects, manufacturers and Asian, homeopathic, } \\
\text { and Indian index. Monographs contain actions, } \\
\text { uses, precautions (with drug interactions), } \\
\text { adverse drug reactions, and contraindications. } \\
\text { There is a separate drug-herb interactions list } \\
\text { and a pictorial herb identification guide. }\end{array}$ \\
\hline $\begin{array}{l}\text { Professional's } \\
\text { Handbook } \\
\text { of Complementary and } \\
\text { Alternative M edicine }\end{array}$ & $\begin{array}{l}2001 \\
\text { 2nd edition }\end{array}$ & $1-58255098-0$ & Handbook & Yes & $\begin{array}{l}\text { Contains alternative substances. Monographs } \\
\text { list actions, uses, dosage, side effects, drug } \\
\text { interactions, special considerations, precautions, } \\
\text { and analysis. Drug-interaction section includes } \\
\text { whether the combination should be given } \\
\text { with caution, patient monitoring is required, } \\
\text { or the combination should be avoided. Appendices } \\
\text { such as a table of therapeutic monitoring } \\
\text { guidelines (e.g., labs to monitor), and an herb } \\
\text { information sheet that can be copied and } \\
\text { individualized for patients. }\end{array}$ \\
\hline $\begin{array}{l}\text { The German Commission } \\
\text { E M onographs: } \\
\text { Therapeutic Guide to } \\
\text { Herbal M edicines }\end{array}$ & $\begin{array}{c}1998 \\
\text { 1st edition }\end{array}$ & $0-9655555-0-X$ & $\begin{array}{l}\text { Hardbound } \\
\text { (CD-ROM } \\
\text { also } \\
\text { available) }\end{array}$ & No & $\begin{array}{l}\text { Contains } 327 \text { monographs on herbals, } 191 \text { with } \\
\text { a favorable listing. There are an additional } 108 \\
\text { unapproved herbs. Monographs include uses, } \\
\text { side effects, drug interactions, dosage, and } \\
\text { contraindications. There is also a drug-herb } \\
\text { interaction table. }\end{array}$ \\
\hline
\end{tabular}


TA B LE 5 Free Alternative-Medicine Web Sites

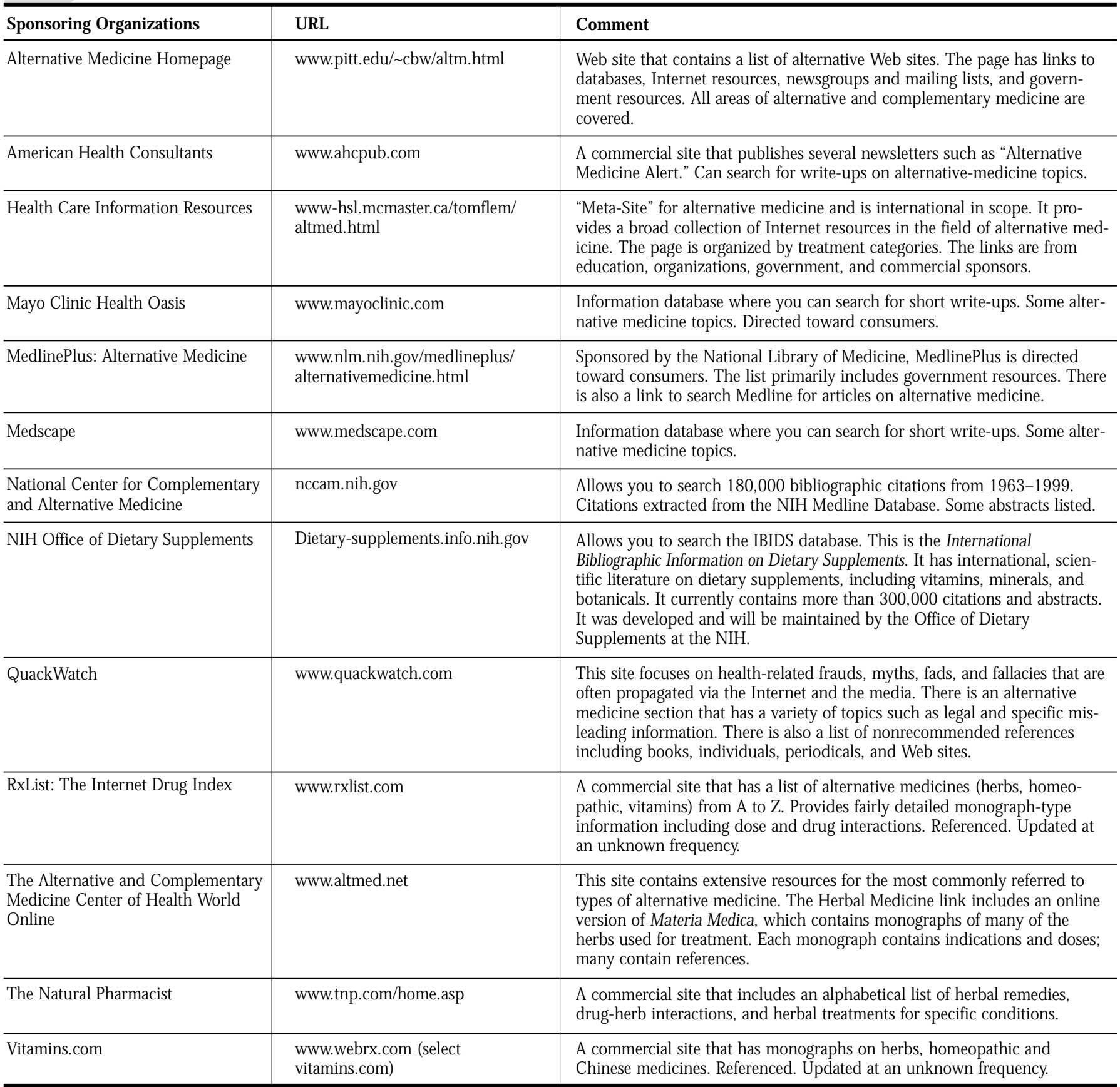

Other patients may experience severe adverse effects. For example, in 1992, prior to DSHEA, the FDA warned several major manufacturers to stop producing dietary supplements containing guar gum after numerous reports of health problems and at least one death from esophageal obstruction associated with the products. ${ }^{15}$ In 1994, the year that DSHEA was approved, Jin Bu Huan herbal tablets, which were promoted as a sedative, were directly linked to severe liver toxicity in both adults and children. ${ }^{15}$ More recently, reports of injury and death in adolescents and young adults due to use and misuse of ma-huang or ephedra have caused the FDA to restrict the advertising practices of manufacturers. ${ }^{15}$

Some of the risks associated with natural products can be eliminated or decreased with close attention to quality. Whenever possible, natural products should meet the same standards as FDA-approved pharmaceuticals. At a minimum, these standards should include the presence of lot numbers, expiration dates, 
standardized ingredients, exact contents including weights or volumes and concentrations, and contact information of the manufacturer. Ideally, pharmacists and other clinicians making recommendations to patients or coverage decisions should first be able to review product literature and double-blinded randomized, placebo, and gold-standard controlled clinical trials. In many cases that information is not available. As with OTC and prescription products, choices of which products and/or product lines to recommend or provide coverage for may be based on the manufacturer's reputation. Large pharmaceutical companies are beginning to manufacture and market natural products. This option may some day allow the inclusion of reputable natural products with good quality-assurance processes in negotiated groupings or bundles. Until then, practitioners must be familiar with current products and the literature and information resources available for making decisions. Fortunately there are growing numbers of resources available to aid practitioners as they struggle with the tough decisions on natural products.

\section{Information Resources}

The amount of information concerning natural products has grown exponentially, making it almost impossible for reviewers to check every reference. However, there are a number of good references available in hard copy, on CD-ROM, and online. Some are listed in Table 4, page 417, and Table 5, page 418. These references are listed in alphabetical order by title rather than in order of importance. As with the natural products themselves, several key components should be examined when evaluating an information resource for natural products. These components include the reputations of the publisher, editors, and authors; the frequency with which the reference is updated; and whether the information is referenced. These key points should help to determine whether the information is current, correct, and unbiased, but cannot guarantee that. Reviewers will al ways need to use clinical judgment when new references or information sources are encountered.

\section{Conclusion}

Even with all of the questions that have been raised in the past ten years regarding natural products, there remains a common misconception among some health professionals, the public, and, based on the intent of DSHEA, some members of the U.S. Congress. That misconception is that "natural means safe." Historically, this has not always proven to be true. And, recently reports of illnesses and deaths attributed to the use or misuse of natural products have increased. When natural products are recommended or provided, some of the inherent risks can be minimized by insisting on products from manufacturers that adhere to good manufacturing practices and those that have a reputation for consistently high-quality products. Risks to patients can be reduced when reliable information and guidance is provided by health care professionals. In the absence of quality information from trained health care providers, patients may turn to other sources. Potential sources include family members, friends, the Internet, employees of exercise and nutrition centers and health food stores, advertisements in popular magazines, and brochures developed by naturalproduct manufacturers.

The popularity of natural products is likely to grow, and MCOs and pharmacists are well positioned to take an active role in the safe and effective use of natural products. However, there is a lack of consensus in the medical community about the use of natural products rather than, or in addition to, medications. The points to consider include, but are not limited to, potential therapeutic uses, probable effectiveness, appropriate doses, monitoring parameters, adverse effects, potential interactions, the risk of adulteration or contamination, and the risk to patients and practitioners when standard medical practices are not followed. Therefore, it is important whenever natural products are recommended or provided, that they be produced by reputable manufacturers of high-quality products that meet the standards for good manufacturing practices and product documentation. In addition, practitioners must use as many reliable resources as possible to support the ongoing study of these products and to help ensure that their decisions are made using correct and up-to-date information.

\section{References}

1. Tyler VE. What pharmacists should know about herbal remedies. J Am Pharm Assoc 1996; NS36: 29-37.

2. Department of Health and Human Services: Office of Inspector General. Adverse event reporting for dietary supplements: An inadequate safety valve. Full report available online at http://oig.hhs.gov/oci/reports/a519.pdf.

3. Gebhart F. Study may have identified St. John's wort power source. Drug Topics 1998; 142: 47

4. Product Review: Echinacea. Available online at www.consumerlabs.com/results/echincacea.asp. Accessed 8/3/2001.

5. Product Review: Ginkgo Biloba. Available online at www.consumerlabs.com/results/ginkgobiloba.asp. Accessed 8/3/2001.

6. Product Review: Asian and American Ginseng. Available online at www.consumerlabs.com/results/ginseng.asp.

7. Harkey MR et al. Variability in commercial ginseng products: An analysis of 25 preparations. Am J Clin Nutr 2001; 73: 1101-06.

8. Adebowale $A O$ et al. Analysis of glucosamine and chondroitin sulfate content in marketed products and the caco-2 permeability of chondroitin sulfate raw materials. J Am Neutraceut Assoc 2000; 3: 37-44.

9. Product Review: Glucosamine and Chondroitin. Available online at www.consumerlabs.com/results/gluco.asp. Accessed 8/3/2001.

10. $\mathrm{Hahm} \mathrm{H}$ et al. Comparison of melatonin products against USP's nutritional supplements standards and other criteria. J Am Pharm Assoc 1999; 39: 27-31.

11. Suhner $A$ et al. Over-the-counter melatonin-quality or quackery? Pharmazie 1999; 54: 863-64.

12. Product Review: St. John's wort. Available online at www.consumerlabs.com/results/sjw.asp. Accessed 8/3/2001.

13. Product Review: Saw palmetto. Available online at www.consumerlabs.com/results/sawpalmetto.asp. Accessed 8/3/2001.

14. Product Review: Valerian. Available online at www.consumerlabs.com/results/valerian.asp. Accessed 8/3/2001.

15. Williamson JS, Wyandt CM. Herbal therapies: the facts and the fiction. Drug Topics 1997; 141: 78-87. 


\section{E $\quad E \quad X \quad A \quad M$}

Upon completion of this article, the successful participant should be able to:

1. Explain the differences between regulations aimed at natural medicines and those aimed at over-the-counter and prescription medications.

2. Describe the limitations of the Dietary Supplement Health and Education Act (DSHEA).

3. List four quality issues associated with natural products.

4. Characterize five options for managing natural products in a managed care population.

5. Discuss resources for locating information on natural products.

\section{SELF-ASSESSMENT QUESTIONS}

1. The 1962 amendment to the U.S. Food, Drug, and Cosmetic Act was designed to help ensure that medications approved for use in the United States are:
a. safe for use.
b. efficacious for the approved indications.
c. safe for use and efficacious for the approved indications.
d. none of the above.

2. DSHEA of 1994 was designed to help ensure that natural products used in the United States are:
a. safe for use
b. efficacious for the approved indications.
c. safe for use and efficacious for the approved indications.
d. none of the above.

3. Under DSHEA, the Food and Drug Administration (FDA) may remove a natural product from the U.S. market if:

a. long-term use fails to show that it is efficacious.

b. the product has been shown to be hazardous for use in humans.

c. there are variations or abnormally low concentrations of the active ingredients in the samples tested.

d. all of the above.
4. Under DSHEA, for which of the following categories of natural products must manufacturers notify the FDA of their intent to market the product at least 75 days prior to marketing and include safety information?

a. new dietary supplement ingredients (i.e., those never before marketed as a food or food substance)

b. new combinations of natural products (i.e., those produced when constituents of several currently marketed plant species are combined)

c. new chemical entities (e.g., those developed during new drug research)

d. all of the above

5. From a managed care organization's or a pharmacists perspective, the differences between the 1962 Food, Drug and Cosmetic Act amendments and DSHEA are:

a. There are greater assurances of safety and efficacy of natural products marketed under DSHEA than for products approved and marketed under the 1962 amendment.

b. There are greater assurances of safety and efficacy of prescription products approved and marketed under the 1962 amendment than for products marketed under DSHEA.

C. Neither the 1962 amendment nor DSHEA provides any assurances of safety and efficacy.

d. Both the 1962 amendment and DSHEA are equally effective in providing assurances of safety and efficacy.

6. Limitations of current natural products include all of the following EXCEPT:

a. Products may not be standardized for purity or potency.

b. Products may be adulterated.

c. Crop conditions may cause batch-tobatch and year-to-year variability in the products.

d. Because of the risk of contamination, most of the products have been rated category " $\mathrm{X}$ " for use during pregnancy.
7. When considering qual ity issues associated with the use of natural products, studies of products containing St. John's wort have shown:

a. that the active ingredient has definitely been shown to be hypericin.

b. that more than $75 \%$ of products tested passed all criteria for quality.

c. that some products contained unacceptably high levels of cadmium.

d. all of the above.

8. Some of the risks associated with providing natural products as a covered benefit or from recommending the use of natural products rather than prescription medications can be reduced by:

a. selecting natural products that meet the same standards as would be required of FDA-approved pharmaceuticals.

b. extensive review of manufacturer and product documentation and review of scientific and medical literature for safety and efficacy comparisons.

c. selecting natural products that are produced by manufacturers with reputations for producing safe products that are of high quality.

d. all of the above.

9. Information resources for natural products should be reviewed for all of the following EXCEPT:

a. the availability of references.

b. National Library of Medicine approval.

c. the reputations of the publishers and authors.

$d$. the frequency with which the resource is updated.

10. The popularity of natural products is likely to:

a. increase from its current standing.

b. decrease as the population ages.

c. remain about the same.

pharmaceutical education. Individuals may obtain up to 1 contact hour of credit or 0.10 Continuing Education Unit (CEU). The Universal Program Number is 233-000-01-005-H01. Certificates will be mailed within eight weeks to participants who successfully complete the CE exam and achieve a score of $70 \%$ and submit the exam to AMCP prior to October 31, 2002. See the text of the article beginning on page 414. 


\section{DEMOGRAPHIC INFORM ATION (not for scoring)}

11. In what type of setting do you work? (Leave blank if none of the responses below applies.)
a. HMO
b. PPO
c. Indemnity insurance
d. Pharmacy benefits management
e. Other

12. Did this program achieve its educational objectives?
a. Yes
b. No

13. How many minutes did it take you to complete this program, including the quiz? (Fill in on answer sheet.)
14. Did this program provide insights relevant or practical for you or your work?
a. Yes
b. No

15. Please rate the quality of this $\mathrm{CE}$ article.
a. Excellent
c. Fair
b. Good
d. Poor

\section{INSTRUCTIONS}

BE This test affords 1 hour $(0.10 \mathrm{CEU})$ of continuing pharmaceutical education in all states that recognize the American Council on Pharmaceutical Education. To receive credit, you must score at least $70 \%$ of your test answers correctly. To record an answer, darken the appropriate block below. Mail your completed answer sheet to: Academy of Managed Care Pharmacy, 100 N. Pitt Street, Suite 400, Alexandria, VA 22314. If you score 70\% or more, a certificate of achievement will be mailed to you within eight weeks. If you fail to achieve $70 \%$ on your first try, you will be allowed only one retake. The ACPE Provider Number for this lesson is 233-000-01-005-H01. This offer of continuing education credit expires October 31, 2002.
A $\quad$ B $\quad$ C $\quad$ D
1. $\square \quad \square \quad \square \quad \square$
2. $\square \quad \square \quad \square \quad \square$
3. $\square \square \square \square$
4. $\square \quad \square \quad \square \quad \square$
5. $\square \square \square \square$
6. $\square \square \square \square$
7. $\square \quad \square \quad \square \quad \square$
8. $\square \quad \square \quad \square \quad \square$
9. $\square \quad \square \quad \square \quad \square$
10. $\square \square \square$

Participant Identification: Please type or print.
11. $\square \mathrm{A} \quad \square \mathrm{B} \quad \square \mathrm{C} \quad \square \mathrm{D} \quad \square \mathrm{E}$

12. $\square$ Yes $\square$ No

13. Minutes

14. $\square$ Yes $\square$ No

15. $\square \mathrm{A} \quad \square \mathrm{B} \quad \square \mathrm{C} \quad \square \mathrm{D}$

Social Security \#:

Date:

Work Phone \#:

Name:

For Identification Purposes Only

LAST FIRST MIDDLE

Company:

Address:

$\begin{array}{lll}\text { STREET (with Apt. No.) or P.O. Box CITY STATE } & \end{array}$
ZIP

State \& Lic. No.:

STATE LICENSE NO.

Member Type: $\square$ Active $\quad \square$ Supporting Associate $\square$ Student $\square$ Nonmember

Signature:

I verify by my signature above that I have completed this examination independently.

Note: If you w ish you can now take this CE Exam online. Go to w w w .amcp.org. 